\title{
СОЗДАНИЕ И ИСПОЛЬЗОВАНИЕ ЭКОЛОГИЧЕСКИХ КАРТ ДЛЯ ИССЛЕДОВАНИЯ ЗАГРЯЗНЕНИЯ ПОЧВ Г. МОСКВЫ
}

\section{Ольга Николаевна Николаева}

Российский государственный аграрный университет - МСХА им. К.А. Тимирязева, Институт мелиорации, водного хозяйства и строительства имени А.Н. Костякова, 127550, Россия, г. Москва, ул. Тимирязевская, 49, доктор технических наук, профессор кафедры экологической безопасности и природопользования, тел. (499) 976-09-37;

Сибирский государственный университет геосистем и технологий, 630108, Россия, г. Новосибирск, ул. Плахотного, 10, профессор кафедры экологии и природопользования, тел. (383)361-08-86, e-mail: onixx76@mail.ru

\section{Татьяна Степановна Король}

Институт мелиорации, водного хозяйства и строительства им. А.Н. Костякова, РГАУ - МСХА им. К.А. Тимирязева, 127550, Россия, г. Москва, ул. Тимирязевская, 49, кандидат биологических наук, доцент, тел. (499)976-09-37, e-mail: tskorol@gmail.com

\section{Кира Дмитриевна Шаховская}

Институт мелиорации, водного хозяйства и строительства им. А.Н. Костякова, РГАУ - МСХА им. К.А. Тимирязева, 127550, Россия, г. Москва, ул. Тимирязевская, 49, обучающийся, тел. (916)739-00-80, e-mail: sh.kira2014@yandex.ru

В статье рассмотрены вопросы использования цифровых экологических карт для анализа состояния почв крупных населенных пунктов. Приведены общие сведения о современном экологическом состоянии почв в Москве, проанализирована оценка уровня химического загрязнения почв, обосновано применение геоинформационных технологий для упрощения восприятия информации. Представлены цифровые экологические карты, характеризующие состояние почв Москвы, созданные в ГИС «MapInfo Professional».

Ключевые слова: почва, загрязнение почв, нефтепродукты, экологическое картографирование, экология почв, техногенное загрязнение, геоинформационное картографирование

\section{CREATION AND USE OF ECOLOGICAL MAPS TO STUDY SOIL POLLUTION IN MOSCOW}

\section{Olga N. Nikolaeva}

Russian State Agrarian University - Moscow Timiryazev Agricultural Academy, Institute of Amelioration, water management and construction named after A.N. Kostyakov, 49, Timiryazevskaya St., Moscow, 127550, Russia, Professor, Department of Environmental Safety and Natural Resources Management; phone: (499)976-09-37, e-mail: onixx76@mail.ru;

Siberian State University of Geosystems and Technologies, 10, Plakhotnogo St., Novosibirsk, 630108, Russia, D. Sc., Professor, The Department of Ecology and Natural Resources Management, phone: (383)361-08-86

\section{Tatiana S. Korol'}

Russian State Agrarian University - Moscow Timiryazev Agricultural Academy, 49, Timiryazevskaya St., Moscow, 127550, Russia, Ph. D., Associate Professor, phone: (499)976-09-37, e-mail: tskorol@gmail.com 


\section{Kira D. Shakhovskaya}

Russian State Agrarian University - Moscow Timiryazev Agricultural Academy, 49, Timiryazevskaya St., Moscow, 127550, Russia, Student, phone: (916)739-00-80, e-mail: sh.kira2014@yandex.ru

The article deals with the use of digital ecological maps for analyzing the state of soils in large settlements. General information about the current ecological state of soils in Moscow is given, the assessment of the level of chemical contamination of soils is analyzed, the use of geoinformation technologies is justified to simplify the perception of information. Presented are digital ecological maps characterizing the state of Moscow soils, created in the GIS "MapInfo Professional".

Keywords: soil, soil pollution, oil products, ecological mapping, soil ecology, technogenic pollution, geoinformation mapping

Развитие транспортных сетей, рост объемов бытовых отходов, деградация природных ландшафтов, воздействие атмосферных осадков и сточных вод приводят к всё более растущей антропогенной нагрузке на почвенный покров и являются открытыми вопросами в области экологической безопасности [3, 22]. Естественный почвенный покров на большей части урбанистических земель буквально истреблен и сохранился только в виде небольших островков в городских лесопарках и ООПТ на территории крупных городов.

Повышенное содержание в почве химических и радиоактивных соединений, различных патогенных организмов, не могут не оказывать влияния на состояние здоровья человека, окружающей среды и качество сельскохозяйственной продукции $[3,27]$. Интенсивное антропогенное воздействие на почвы объясняет необходимость детального анализа взаимодействия человека и почвенных экосистем [28].

Сегодня в почвенном покрове Москвы происходит формирование так называемых урбанозёмов - почв с нарушенным строением профиля, несоответствующим залеганием горизонтов, наличием антропогенных горизонтов с огромной загрязнённостью тяжёлыми металлами и органическими веществами, строительными и бытовыми загрязнителями $[2,4]$.

Заинтересованность в оценке состояния почвенного покрова отмечена во многих научных трудах современных исследователей, общий анализ показывает устойчивую тенденцию загрязнения почв бывших промышленных районов, а также зон, прилегающих к автомагистралям.

В обзорных статьях, посвященных анализу состояния почв за последние годы зачастую приводится оценка состояния почвенного покрова на основе суммарного показателя загрязнения (Zc), который характеризуется допустимым уровнем на территории большей части административных районов Москвы. Максимальное число проб с превышением нормативов по цинку, обладающему повышенной токсичностью при высоких концентрациях, отмечается в почвах общественных и жилых функциональных зон [6, 7]. Почвенный покров парков и ООПТ менее подвержен данным воздействиям, что объясняется удаленным расположением таких зон от промышленных центров и крупных магистралей. Однако даже тут не исключаются существенные концентрации загрязняющих веществ. 
Мониторинг обеспечивает получение максимально полной информации, которая характеризует современное состояние почв на территории города, а также позволяет вовремя отследить негативные изменения состояния почвы и выявить наиболее актуальные проблемы в данной области [9, 21].

В настоящее время данные, которыми можно воспользоваться при анализе экологической обстановки приведены в Ежегодных отчетах о состоянии окружающей среды Российской Федерации и ее отдельных регионов. Для систематизации и наглядности этих сведений удобно использовать экологические карты [5].

Геоинформационное картографирование является одним из ведущих направлений современного анализа данных, так как позволяет визуализировать и связывать огромное количество информации, пополнять обновляющуюся базу данных, производить ее обработку и анализ. Геоинформационное картографирование прежде всего проявляется в комплексном картографировании исследуемых явлений и объектов, основу которого составляет создание серии согласованных, сопоставимых и взаимодополняющих карт и атласов $[10,24]$.

Одной из целей проведения комплексных экологогеохимических исследований, в частности, почвенного мониторинга является создание эколого-геохимической карты и карт распределения загрязняющих веществ с применением геоинформационных технологий. Данные карты отображают ареалы зон, районов с выявленными геохимическими аномалиями токсикантов. Они позволяют решать весь комплекс эколого-геохимических задач [11, 12].

В ходе исследований нами были собраны и систематизированы сведения о загрязнении почв г. Москвы тяжелыми металлами, бензапиреном и нефтепродуктами. Далее эти сведения анализировались в ГИС, чтобы установить районы Москвы, характеризующиеся наиболее высоким загрязнением почв. Для работы использовалась ГИС «MapInfo Professional», благодаря которой можно создавать и редактировать карты, хранить и обрабатывать информацию, связанную с картографическими объектами $[8,13]$. В этой ГИС были созданы 3 экологические карты, отражающие загрязнение почв Москвы бензапиреном, тяжелыми металлами и нефтепродуктами.

На рис. 1 приведена карта, посвященная загрязнению почв нефтепродуктами. Это очень важный для современных городов вид загрязнения, который вызван влиянием промышленности различных спектров, производством энергии, постоянным приростом транспорта. Легенда карты представлена в виде табл. 1.

Таблий 1

Концентрации нефтепродуктов в почвах Москвы

\begin{tabular}{|c|c|}
\hline & $110-130 \mathrm{мг} / \mathrm{\kappa} \Gamma$ \\
\hline & $100-110 \mathrm{M \Gamma} / \mathrm{\kappa} \Gamma$ \\
\hline & $71-100 \mathrm{м} \Gamma / \mathrm{\kappa} \Gamma$ \\
\hline
\end{tabular}




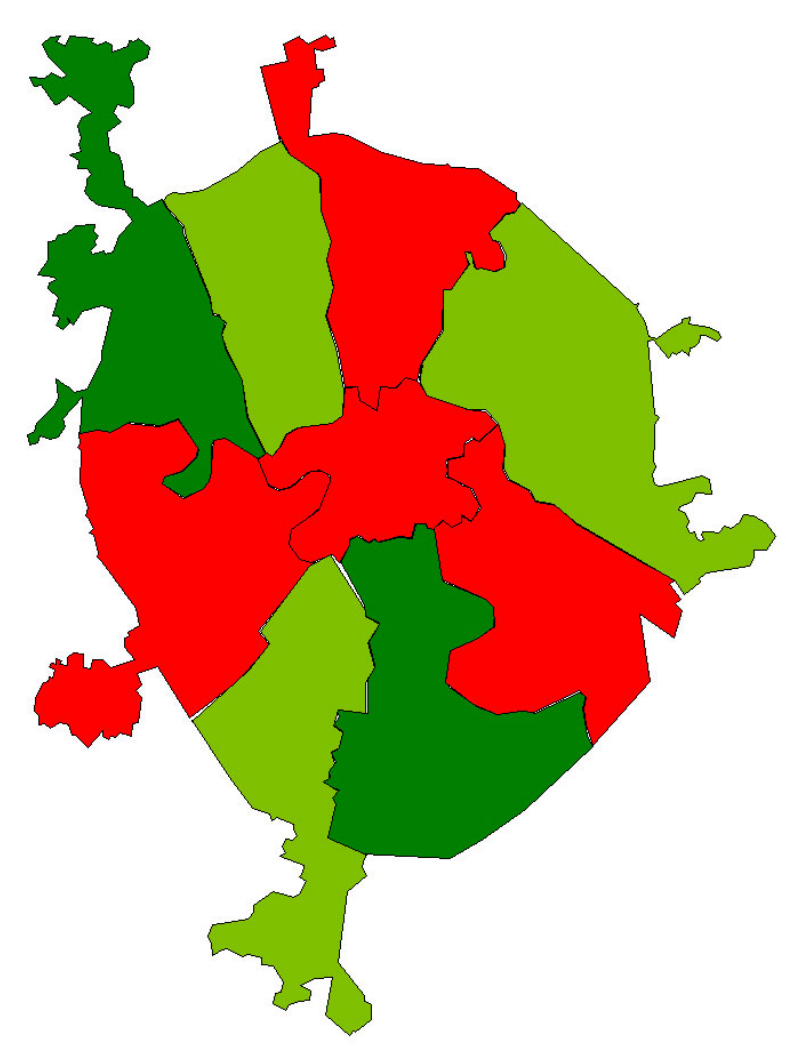

Рис. 1. Загрязнение почв административных округов г. Москвы нефтепродуктами

По данным, указанным в отчете за 2019 год [14], ПДК нефтепродуктов в почвах не превышены, наибольшие концентрации присутствуют на территории СВАО, ЦАО, ЮВАО и ЗАО, которые выделены на карте красным цветом.

Аналогичным образом были составлены еще 2 экологические карты, характеризующие суммарный показатель загрязнения почв тяжелыми металлами (Zc) и бензапиреном.

Далее было выполнено ранжирование административных округов на основе 3 расчетных показателей: суммарного показателя загрязнения (Zc) $[15,16]$, концентраций бензапирена и нефтепродуктов, чтобы комплексно оценить ситуацию. Каждому загрязнителю была присвоена собственная градация баллов.

С помощью этого подхода была построена карта, изображенная на рис. 2. Легенда к карте приведена в табл. 2.

Таблица 2

Комплексная оценка загрязнения почв

\begin{tabular}{|c|c|}
\hline & $7-10$ баллов \\
\hline & $6-10$ баллов \\
\hline & $0-6$ баллов \\
\hline
\end{tabular}




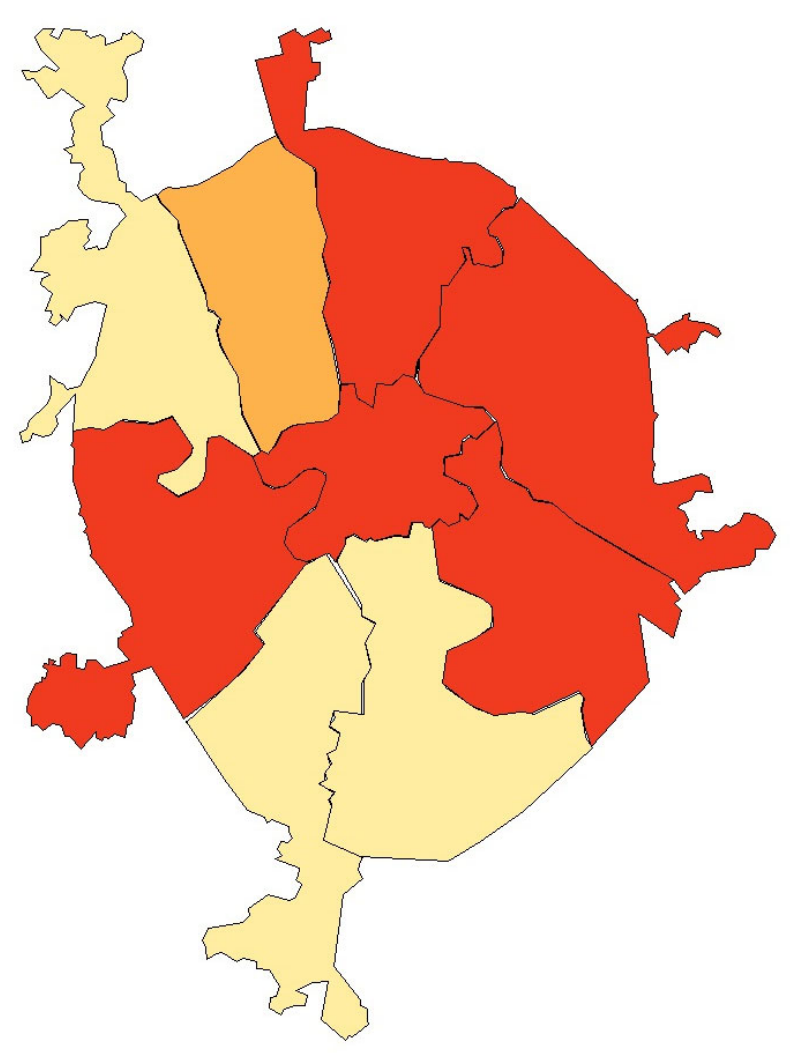

Рис. 2. Результаты комплексной оценки загрязнения почв г. Москвы

По выведенным данным можно сказать, что почвы наиболее загрязнены на территории ЗАО, ВАО, ЦАО, ЮВАО, СВАО, ЗАО.

Работу по составлению карт загрязненности почв г. Москвы можно использовать для анализа экологической обстановки пользователю с минимальным набором знаний в этой сфере, при оценке воздействия на окружающую среду, планировании землепользования, в других природоохранных и производственных мероприятиях $[19,22]$.

Также эта информация может быть интересна широкому кругу пользователей при выборе района для будущего проживания, и как помощь студентам экологической или инженерно-экологической специальности при выполнении исследовательских работ.

\section{БИБЛИОГРАФИЧЕСКИЙ СПИСОК}

1. Гигиеническая оценка качества почвы населенных мест: методические указания MУ 2.1.7.730-99.

2. Малышева Алла Георгиевна, Шелепова О.В., Водянова М.А., Донерьян Л.Г., Ушакова О.В., Юдин С.М. Эколого-гигиенические проблемы применения противогололёдных реагентов в условиях крупного мегаполиса (на примере территории города Москвы) // Гигиена и санитария. 2018. №11. URL: https://cyberleninka.ru/article/n/ekologo-gigienicheskie-problemyprimeneniya-protivogololyodnyh-reagentov-v-usloviyah-krupnogo-megapolisa-na-primereterritorii-goroda (дата обращения: 02.11.2020). 
3. Макаров А.О. Оценка экологического состояния почв некоторых железнодорожных объектов ЦАО г. Москвы: диссертация кандидата биологических наук: 03.02.13 / Макаров Андрей Олегович; [Место защиты: Московский государственный университет им. М.В.Ломоносова]. - Москва, 2014. -282с.

4. Почвы Москвы [Электронный ресурс]: Википедия. Свободная энциклопедия. - URL: https://ru.wikipedia.org/wiki/Почвымосквы (дата обращения: 05.10.2020).

5. Коновалова Татьяна Ивановна Методология исследования и картографирования антропогенной трансформации геосистем // Известия Иркутского государственного университета. Серия: Науки о Земле. 2020.

6. Гладков Е. А. Тяжелые металлы как одни из основных загрязнителей почвенного покрова города Москвы //Auditorium. - 2018. - №. 4 (20).

7. Гладков Е.А., Глушецкая Л.С., Гладкова О.В. Генеральное планирование иэкологические проблемы озеленения городских экосистем (глава в монографии) //Города, окружающая среда и экосистемные эффекты в социально -пространственной динамике современной жизни / под общ. ред. Е.А. Гладкова. Н. Новгород: НОО «Профессиональная наука», 2018.

8. Колесников Сергей Федорович, Сладкопевцев Сергей Андреевич ЭКОЛОГИЧЕСКИЕ КАРТЫ: ПРОБЛЕМЫ, СОДЕРЖАНИЕ, РАЗВИТИЕ // Известия ДГПУ. ЕстественнЫе и точные науки. 2018. №3. URL: https://cyberleninka.ru/article/n/ekologicheskie-karty-problemysoderzhanie-razvitie (дата обращения: 02.11.2020).

9. Состояние почв на основе суммарного показателя загрязнения [Электронный ресурс] URL: https://data.mos.ru/opendata (дата обращения: 04.11.20).

10. Бешенцев Андрей Николаевич, Куклина Евгения Эрдэмовна, Калашников Кирилл Иванович, Балданов Нимбу Доржижапович МОНИТОРИНГ УРБАНИЗИРОВАННОЙ ТЕРРИТОРИИ: МЕТОДЫ, ТЕХНОЛОГИИ, РЕЗУЛЬТАТЫ // Вестник СГУГиТ (Сибирского государственного университета геосистем и технологий). 2020. №2. URL: https://cyberleninka.ru/article/n/monitoring-urbanizirovannoy-territorii-metody-tehnologii-rezultaty (дата обращения: 02.11.2020).

11. Регионы и города России: интегральная оценка экологического состояния / Под редакцией Н. С. Касимова. М. : ИП Филимонов М. В., 2014. - 560 с.

12. Шумилова, М. А. Исследование загрязненности снежного покрова на примере города Ижевска / М. А. Шумилова, О. В. Садиуллина, В. Г. Петров // Вестник Удмуртского ун-та. Сер. Физика. Химия. - 2012. - Вып. 2. - С. 83-89.

13. Почвы и техногенные поверхностные образования в городских ландшафтах / Г.В. Ковалева, В.Т. Старожилов, А.М. Дербенцева, А.В. Назаркина. - Владивосток: Дальнаука, 2012. $159 \mathrm{c}$.

14. Доклад о состоянии окружающей среды в городе Москве в 2019 году / Департамент природопользования и охраны окружающей среды города Москвы. М., 2020.

15. Прокофьева Т.В., Мартыненко И.А., Иванников Ф.А. Систематика почв и почвообразующих пород города Москвы и возможность включения их в общую классификацию // Почвоведение. - 2011. - № 5. - С. 611-623.

16. Состояние почв на основе суммарного показателя загрязнения [Электронный ресурс] URL: https://data.mos.ru/opendata (дата обращения: 01.11.20).

17. Lee N. and Walsh F. Strategic Environmental Assessment: An Overview, Project Appraisal 7(3). 1992.

18. Daniel T. McGrath. Urban Industrial Land Redevelopment and Contamination Risk. Journal of Urban Economics 47, 2000.

19. Documents de la Cartographic Ecologique. Grenoble, 1973-1983. - Vol. XI-XXVI.

20. Barnthouse L. 2008. The strengths of the ecological risk assessment process: Linking science to decision making. Integr Environ Assess Manag 4:299-305.

21. Dovers S. Information, Sustainability and Policy//Australian Journal of Environmental Management. Vol. 2. 1995. P. 142-156. 
22. Leenaers H., Okx J.P., Burrough P.A. Comparision of spatial prediction method for mapping floodplain soil pollytion. Catena, 1990.

23. W. Koch Empirische Methoden zur Erholung der Nutzungseffektivitat von thematischen Karten fur die Planung / Vermessungstechnik 38. Jg. Heft 10 s. (1990). 346-348.

24. Behrens J. Reinhold. A. Computergestutzte Herstellung Thematischer Karten fur Landschaft und okologisch'es Boden-Monitoring. / Vermes-sungstechnik 38. Jg. Heft 10 s. (1990). 340-343.

25. Benedikt M. Rey. Kartographie fur Wirtschaftsunternehmen. Vermessungstechnik 38. Jg. Heft 11 s. (1990). 362-365.

26. Ng, E.-L., Huerta Lwanga, E., Eldridge, S. M., Johnston, P., Hu, H.-W., Geissen, V., \& Chen, D. (2018). An overview of microplastic and nanoplastic pollution in agroecosystems. Science of the Total Environment, 627, 1377-1388.

27. Wall, D. H., Nielsen, U. N., \& Six, J. (2015). Soil biodiversity and human health. Nature, 1-8.

28. Sharma, I. P., Chandra, D., \& Kanta, C. (2018). Drilosphere: A valuable source for soil microbial activities. MOJ Biology and Medicine, 3(4), 3-5.

(C) О. Н. Николаева, Т. С. Король, К. Д. Шаховская, 2021 